Aritoshi Iida - Susumu Saito - Akihiro Sekine

Chisato Mishima • Kimie Kondo • Yuri Kitamura

Satoko Harigae · Saori Osawa • Yusuke Nakamura

\title{
Catalog of 258 single-nucleotide polymorphisms (SNPs) in genes encoding three organic anion transporters, three organic anion-transporting polypeptides, and three NADH:ubiquinone oxidoreductase flavoproteins
}

\begin{abstract}
We present here a series of high-density maps of single-nucleotide polymorphisms (SNPs) detected in genes encoding three organic-anion transporters, three organic anion-transporting polypeptides, and three nicotinamide adenine dinucleotide, reduced:ubiquinone oxidoreductase flavoproteins. A total of 258 SNPs were identified among these nine genes through systematic screening of DNA from 48 Japanese individuals: 17 in $5^{\prime}$ flanking regions, three in $5^{\prime}$ untranslated regions, 13 in coding regions, 211 in introns, six in $3^{\prime}$ untranslated regions, and 8 in $3^{\prime}$ flanking regions. By comparing our data with SNPs deposited in the dbSNP database in the National Center for Biotechnology Information, we determined that $236(91.5 \%)$ were novel. In addition, 46 genetic variations of other types were discovered within these loci. These high-resolution maps will serve as a useful resource for analyzing potential associations between variations in these nine genes and differences in human susceptibilities to common diseases or response to drug therapies.
\end{abstract}

Key words Single-nucleotide polymorphisms (SNPs) · High-density SNP map - Nonsynonymous substitutions · Insertion-deletion polymorphism - Japanese population . Human organic-anion transporter genes - Human organic anion-transporting polypeptide genes $\cdot \mathrm{NADH}$ :ubiquinone oxidoreductase flavoprotein genes

A. Iida $\cdot$ S. Saito $\cdot$ A. Sekine $\cdot$ C. Mishima $\cdot$ K. Kondo $\cdot$ Y. Kitamura $\cdot$ S. Harigae $\cdot$ S. Osawa $\cdot$ Y. Nakamura

Laboratory for Genotyping, RIKEN SNP Research Center, Tokyo, Japan

Y. Nakamura $(\varangle)$

Laboratory of Molecular Medicine, Human Genome Center,

Institute of Medical Science, The University of Tokyo, 4-6-1

Shirokanedai, Minato-ku, Tokyo 108-8639, Japan

Tel. +81-3-5449-5372; Fax +81-3-5449-5433

e-mail: yusuke@ims.u-tokyo.ac.jp

\section{Introduction}

A major goal of the Human Genome Project is to understand the role of common genetic variations as regards susceptibility to common diseases and differences among individuals with respect to therapeutic efficacy and/or side effects of drugs. To achieve this aim, we established two different screening systems to explore single-nucleotide polymorphisms (SNPs) across the human genome. One approach was intended to identify up to 150,000 SNPs within transcription units in the Japanese population; more than 130,000 SNPs have been discovered already and that information (as of the middle of June 2001) is available from our worldwide website (http://snp.ims.u-tokyo.ac.jp/). Second, we focused on variations in genomic regions that correspond to genes encoding drug-metabolizing enzymes and transporters. Approximately 1300 SNPs and other variations within such loci have been reported (Iida et al. 2001a,b,c,d; Saito et al. 2001a,b; Sekine et al. 2001). Moreover, we established a high-throughput system for genotyping up to 100 million SNPs per year, using a multiplex polymerase chain reaction (PCR) method with the Invader assay (Ohnishi et al. 2001). The identification of SNPs at specific loci, coupled with our high-throughput genotyping system, should allow investigators to resolve complex diseases or predict drug responses within a few years.

Organic-anion transporters (OATs) are membrane proteins with 12 putative membrane-spanning domains; these molecules function as sodium-independent exchangers or facilitators, handling a wide variety of clinically important compounds (antibiotics, nonsteriodal anti-inflammatory drugs [NSAIDs]) and toxins (see reviews by Sekine et al. 2000; Sweet et al. 2001). So far, four mammalian OAT isoforms (OAT1, OAT2, OAT3, and OAT4) and one fish isoform (fROAT) have been identified (Sekine et al. 2000). Among them, OAT1 is a $p$-aminohippurate (PAH)/ dicarboxylate exchanger that mediates the high-affinity transport of $\mathrm{PAH}$ in a sodium-independent manner. Human OAT1 (hOAT1) and rat OAT1 (rOAT1) are able 
to transport anionic drugs including cephaloridine (a $\beta$ lactam antibiotic); NSAIDs such as aspirin, indomethacin, and salicylate; methotrexate (an antitumor drug); and penicillin $G$, as well as various endogenous substrates like organic anions, prostaglandin E2 (PGE2), glutarate, $\alpha$-ketoglutarate, cyclic adenosine monophosphate, and cyclic guanosine monophosphate. OAT3, for its part, mediates transport of dehydroepiandrosterone sulfate, ochratoxin A, PGE2, estradiol glucuronide, and glutarate. With a substrate spectrum as diverse as that of OAT1, OAT3 also interacts with anionic metabolites of neurotransmitters such as adrenaline, noradrenaline, and serotonin. Human OAT3 (hOAT3) is located in the basolateral membrane of renal proximal tubules (Cha et al. 2001), where it interacts with chemically heterogeneous anionic compounds including NSAIDs, diuretics, sulfobromophthalein, penicillin $\mathrm{G}$, bile salts, and tetraethyl ammonium bromide. $h O A T 2$ was isolated from a human kidney cDNA library as the counterpart of rat OAT2 (Kok et al. 2000), but its functional properties are not clear.

Organic anion-transporting polypeptide (Oatp1) was first identified in rats as a multispecific and sodium ionindependent transporter for various organic anions including bile acids, conjugated metabolites, and xenobiotics (Jacquemin et al. 1994). Human OATP1 (hOATP1; originally referred to as OATP), an ortholog of rat Oatp1, is localized mainly in brain and liver; it mediates hepatocellular uptake of organic anions including bile acids, sulfobromosulphophthalein (BSP), estrone-3-sulfate, estradiol-17-glucuronide $\left(\mathrm{E}_{2} 17 \beta \mathrm{G}\right)$, the cardiac glycoside ouabain, and even the cationic compound N-(4,4-azo-npentyl)-21-deoxy-ajmalinium (Kullak-Ublick et al. 1995; Bossuyt et al. 1996). Human OATP2 (hOAT2) is also expressed specifically in liver, where it is localized at the basolateral membrane of hepatic parenchymal cells; it plays a crucial role in the sinusoidal uptake of anionic drugs and metabolites (Abe et al. 1999; Hsiang et al. 1999; Konig et al. 2000a; Tamai et al. 2000). Human OATP8 (hOAT8) can transport several typical organic anions, e.g., BSP, $\mathrm{E}_{2} 17 \beta \mathrm{G}$, and dehydroepiandrosterone sulfate, but not bile salts (Konig et al. 2000b). So far, five genes encoding organic anion-transporting polypeptides have been identified in humans (Konig et al. 2000b).

Nicotinamide adenine dinucleotide, reduced (NADH):ubiquinone oxidoreductase (complex I) removes electrons from NADH and passes them on to the electron acceptor ubiquinone. This is the first step in the transfer of electrons, through a number of intermediates, to oxygen, and drives the production of adenosine triphosphate (Walker 1992). Complex I, a complex of integral membrane proteins, is composed of more than 42 subunits, 7 of which are encoded by the mitochondrial genome and the remainder by the nuclear genome (Smeitink and van den Heuvel 1999). Complex I consists of (1) a flavoprotein fraction, containing binding sites for NADH, flavin mononucleotide, and iron-sulfur ( $\mathrm{Fe}-\mathrm{S}$ ) clusters; (2) an iron-protein fraction with several $\mathrm{Fe}-\mathrm{S}$ clusters; and (3) a hydrophobic fraction, which binds quinone, in the inner membrane. The flavoprotein fraction is composed of a $51-\mathrm{kDa}$ subunit (NDUFV1), a 24-kDa subunit (NDUFV2), and a 10-kDa subunit (NDUFV3), all encoded by the nuclear genome (Ali et al. 1993; de Coo et al. 1995, 1997, 1999). This fraction may play a catalytic role in the oxidation of NADH, as it is associated with flavoproteins and NAD binding. Mutation in NDUFV1, NDUFS1, NDUFS4, NDUFS7, or NDUFS8 results in mitochondrial complex I deficiency (OMIM \#252010; Benit et al. 2001). Earlier we constructed highdensity SNP maps of 18 Complex-I gene loci, in which a total of 241 SNPs were identified (Iida et al. 2001b).

In the present report, we provide a series of fine-scale maps of variations within three organic anion-transporter genes, three organic anion-transporting polypeptide genes, and three NADH:ubiquinone oxidoreductase flavoprotein genes. These maps contain a total of 258 SNPs and 46 variations of other types detected in a Japanese population sample.

\section{Subjects and methods}

Blood samples were obtained with written informed consent from 48 healthy Japanese volunteers for this study, which was approved by the ethical committee of the RIKEN SNP Research Center. On the basis of genomic sequences from the GenBank database, we designed primers to amplify each gene in its entirety, as well as $2 \mathrm{~kb}$ upstream of the first exon and downstream of the last exon. However, we excluded from the screening protocol most of the regions corresponding to repetitive sequences predicted by the RepeatMasker program. DNA extraction, PCR experiments, and DNA sequencing were performed according to methods described on our worldwide website (http:// snp.ims.u-tokyo.ac.jp/). Each PCR was carried out using $20 \mathrm{ng}$ of DNA pooled from three individuals. All SNPs detected by the PolyPhred computer program (Nickerson et al. 1997) were confirmed by sequencing both strands of each PCR product.

Genbank accession numbers for OAT, OATP, and $N D U F V$ genomic sequences:

hOAT1: AP001858.3, AJ249369.1, and AP000438.4

hOAT2: AC26532.3

hOAT3: AP001858.3

hOATP1: AC022224.22

hOATP2: NT_024399.2

hOATP8: NT_024399.2

NDUFV1: NT_009304.2

NDUFV2: NT 011024.2

NDUFV3: AP001748.1

\section{Results and discussion}

We present here a series of high-density SNP maps that include a total of 258 SNPs present in a Japanese population sample among nine genes (three hOATs, three hOATPs, and three $N D U F V s$ ) that are involved in the metabolism of 
Human organic anion transporter $1(h O A T l)$

$0 \mathrm{~kb}$

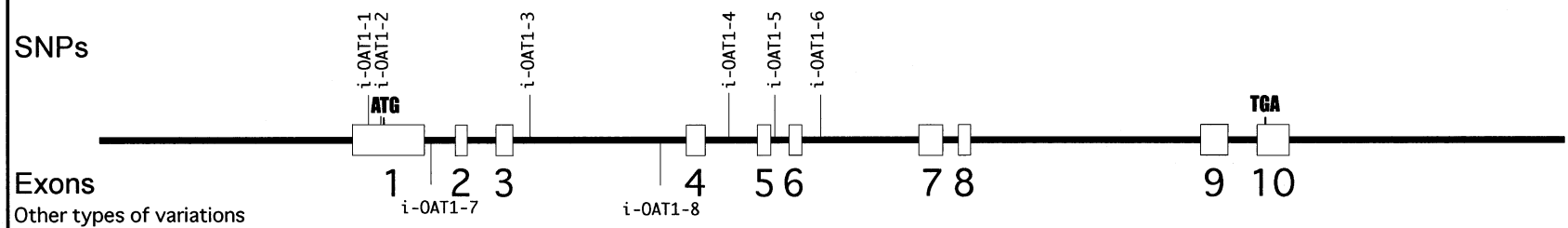

a

\section{Human organic anion transporter $2(h O A T 2)$}

$0 \mathrm{~kb}$

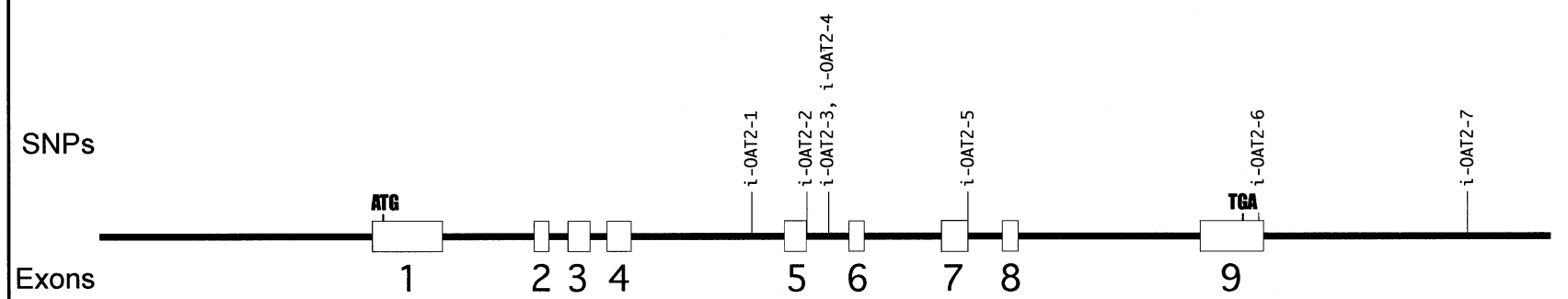

b

\section{Human organic anion transporter 3 (hOAT3)}

$0 \mathrm{~kb}$
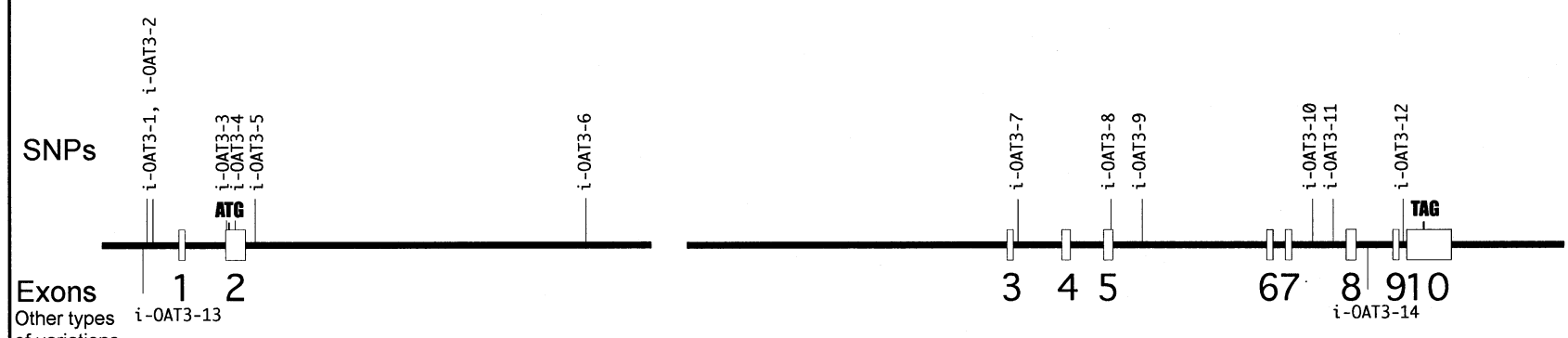

of variations

C

Fig. 1a-i. Genomic organizations and locations of single-nucleotide polymorphisms $(S N P S)$ in nine genes encoding three organic-anion transporters (a-c), three organic anion-transporting polypeptides (df), and three NADH:ubiquinone oxidoreductase flavoproteins (g-i). Detailed information about each variation is given in Table 1. Exons and introns are represented by rectangles and horizontal lines, respectively. SNPs are indicated above the genes (designations correspond to the left-most column on Table 1). Other types of variations, where present, are indicated below the genes 


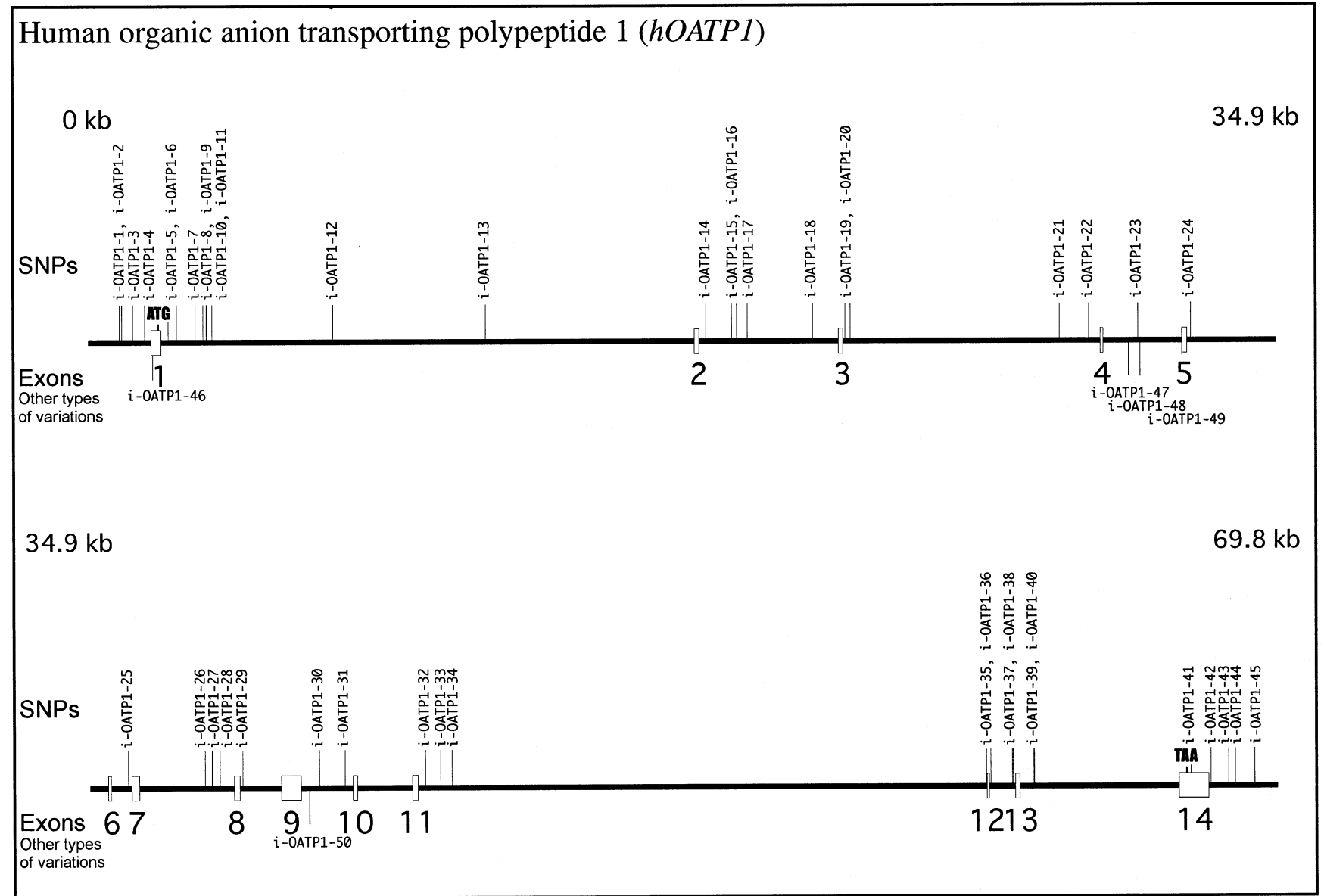

d

Fig. 1a-i. Continued 


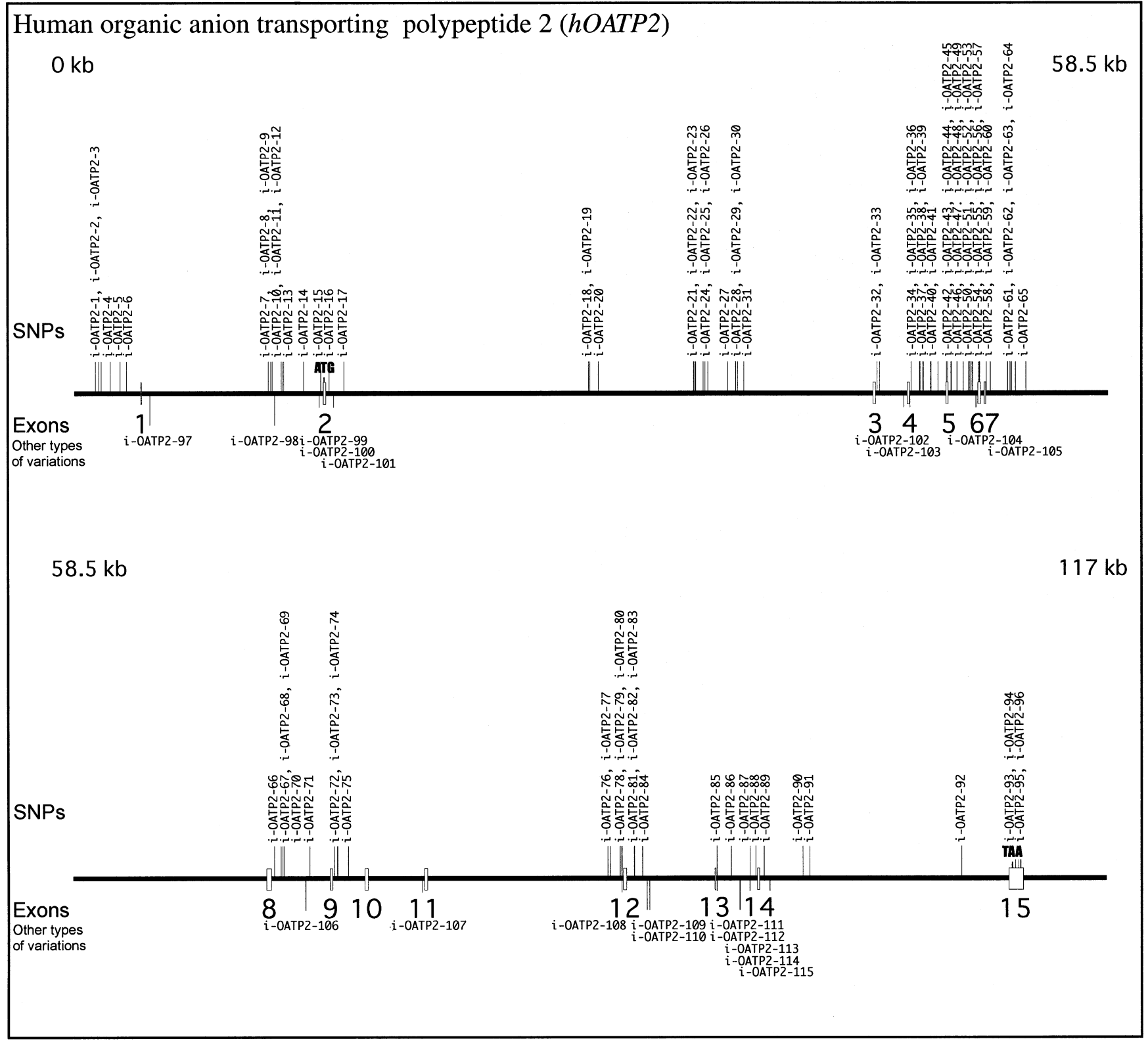

e

Fig. 1a-i. Continued 


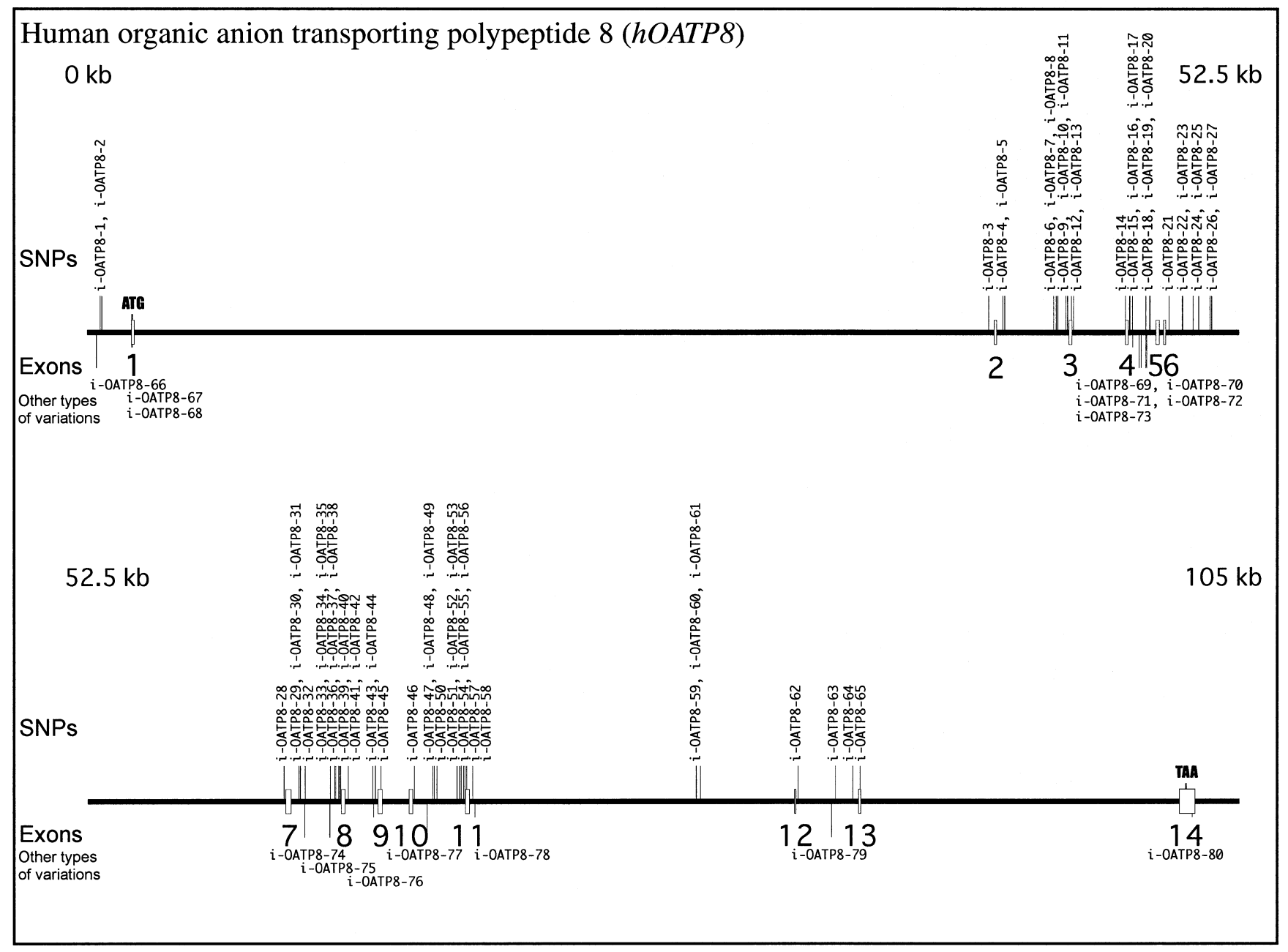

f

Fig. 1a-i. Continued 


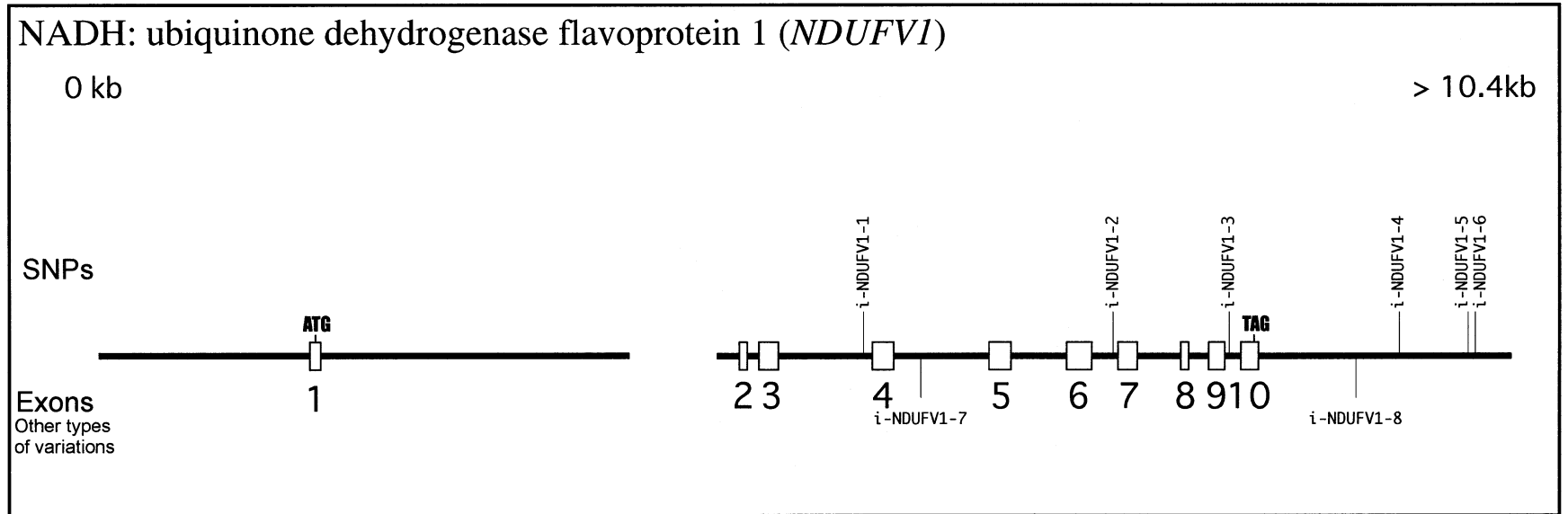

g

NADH: ubiquinone oxidoreductase flavoprotein 2 (NDUFV2)

$0 \mathrm{~kb}$
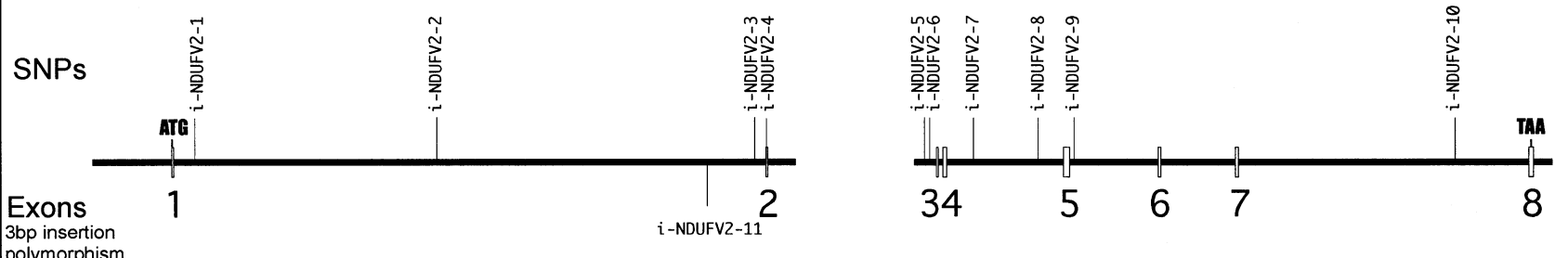

h

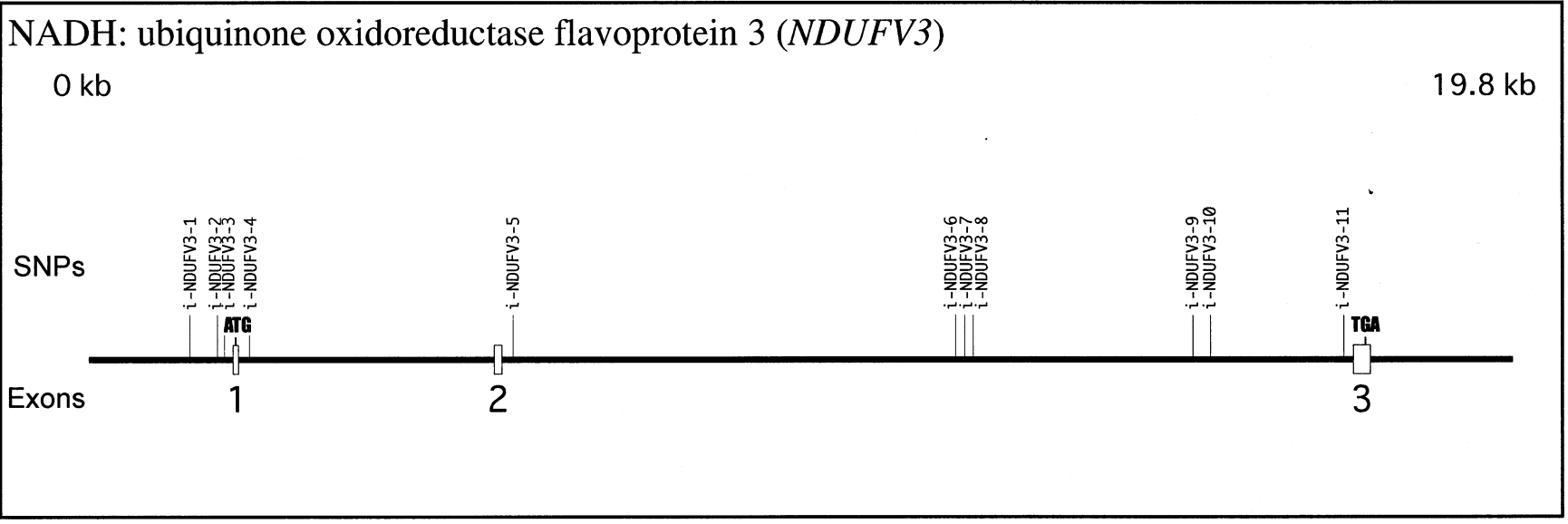

i

Fig. 1a-i. Continued 


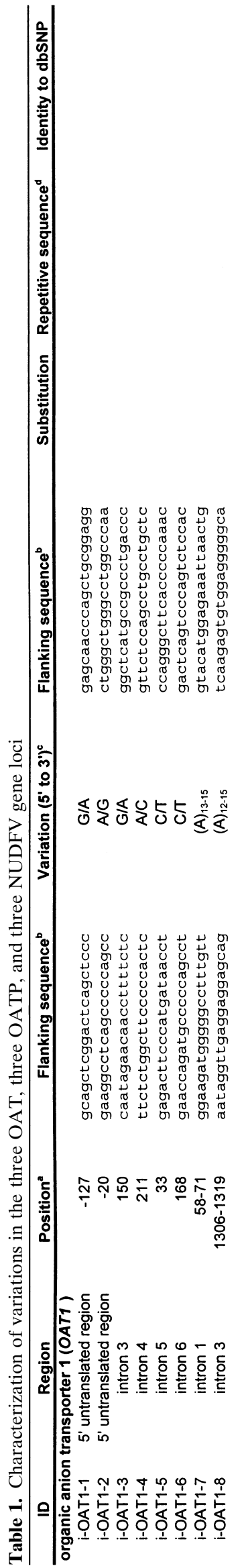

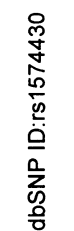

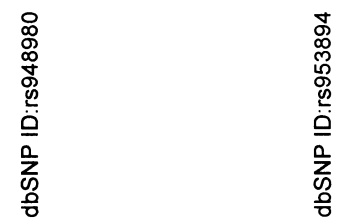

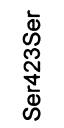

$\frac{5}{2}$
$\frac{2}{5}$
$\frac{5}{2}$
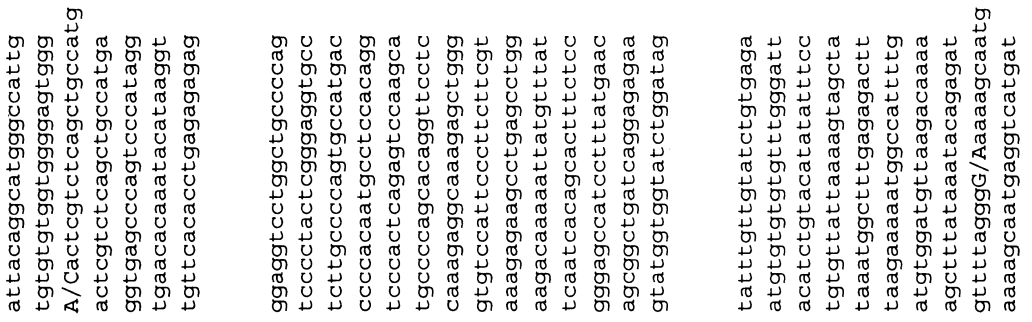

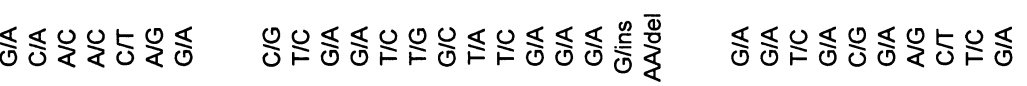
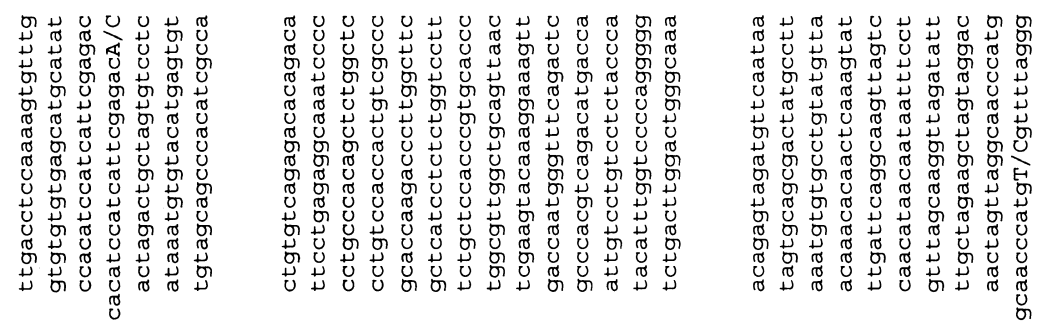

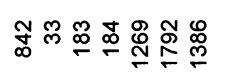

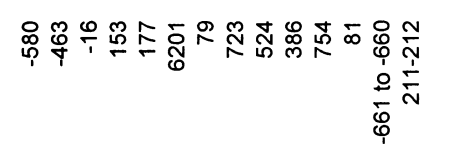
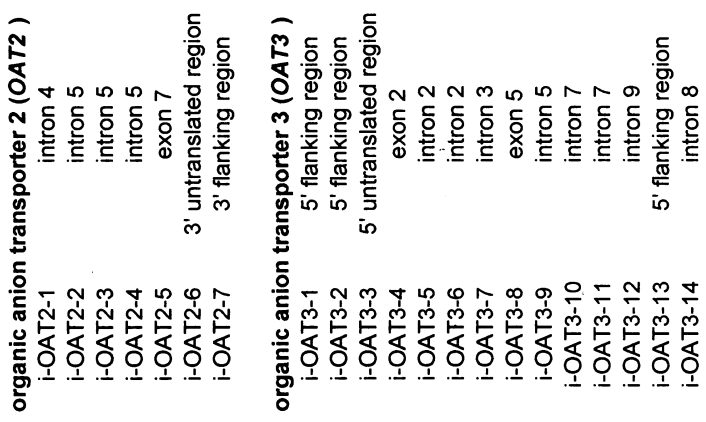

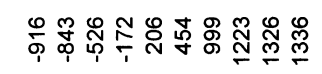

这

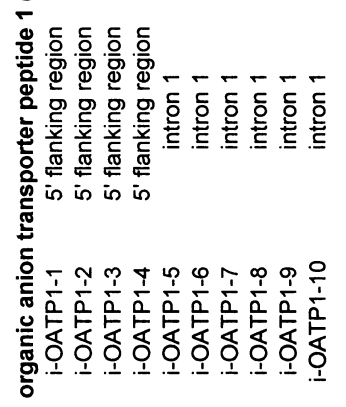




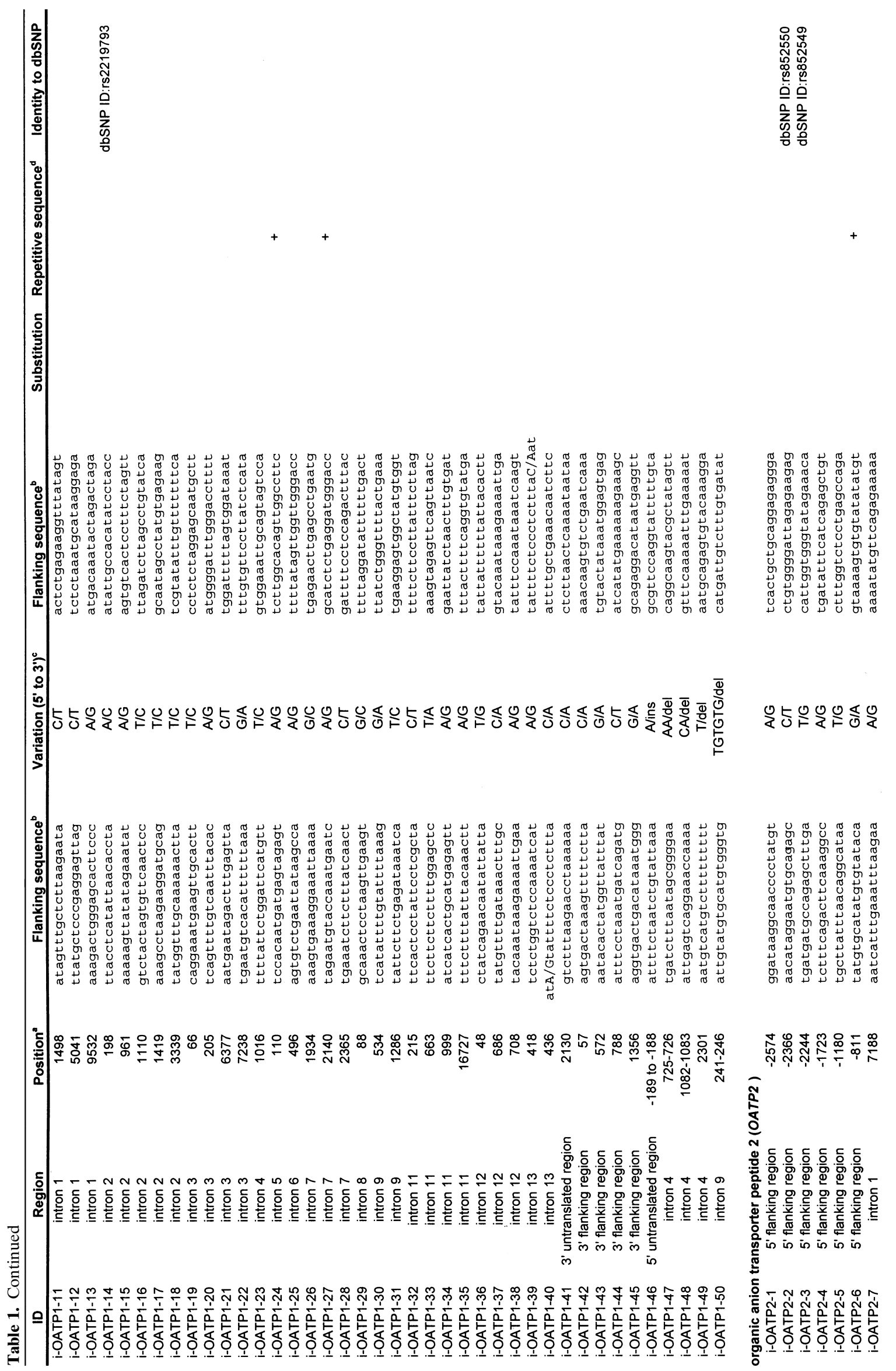




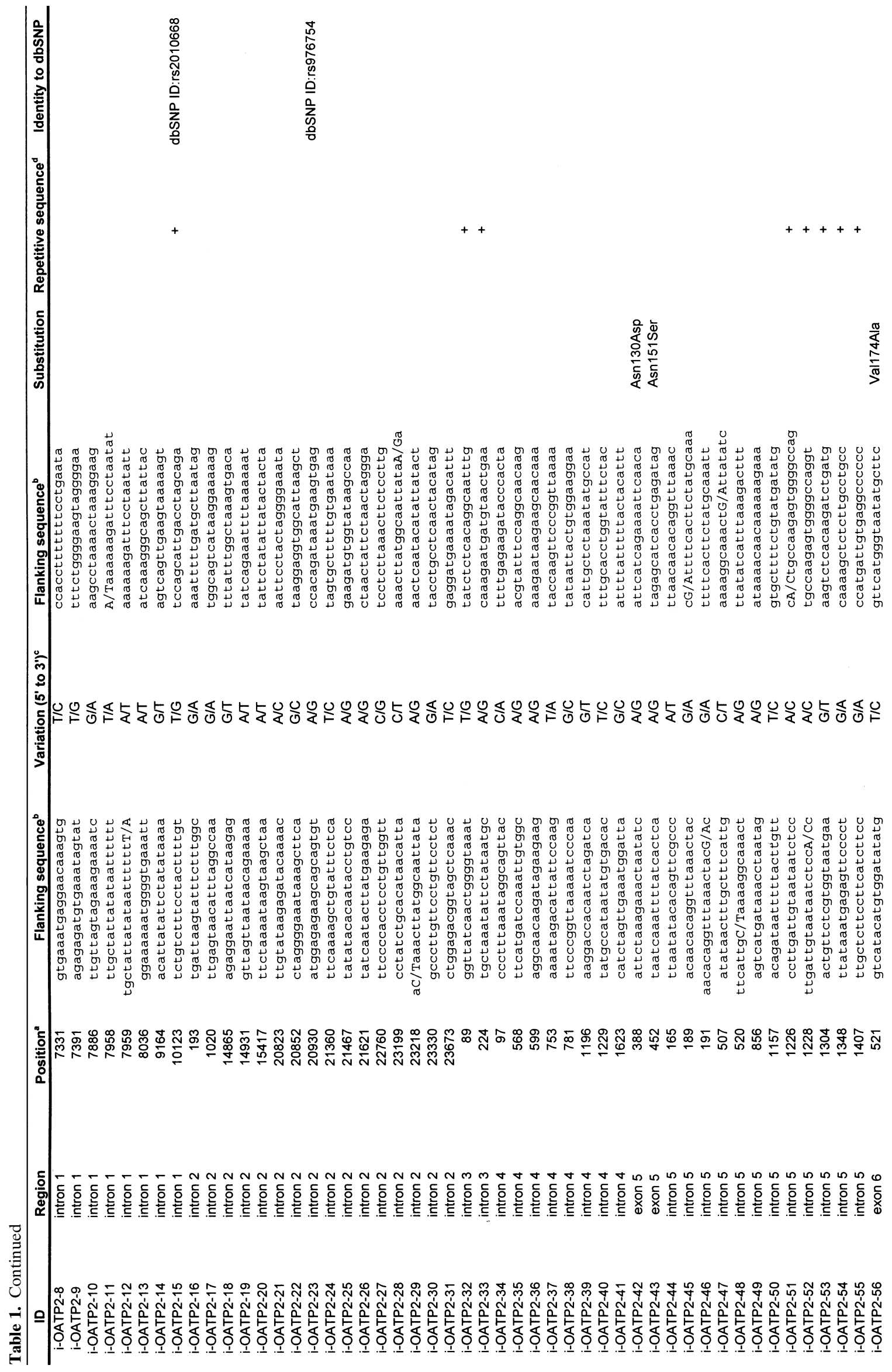




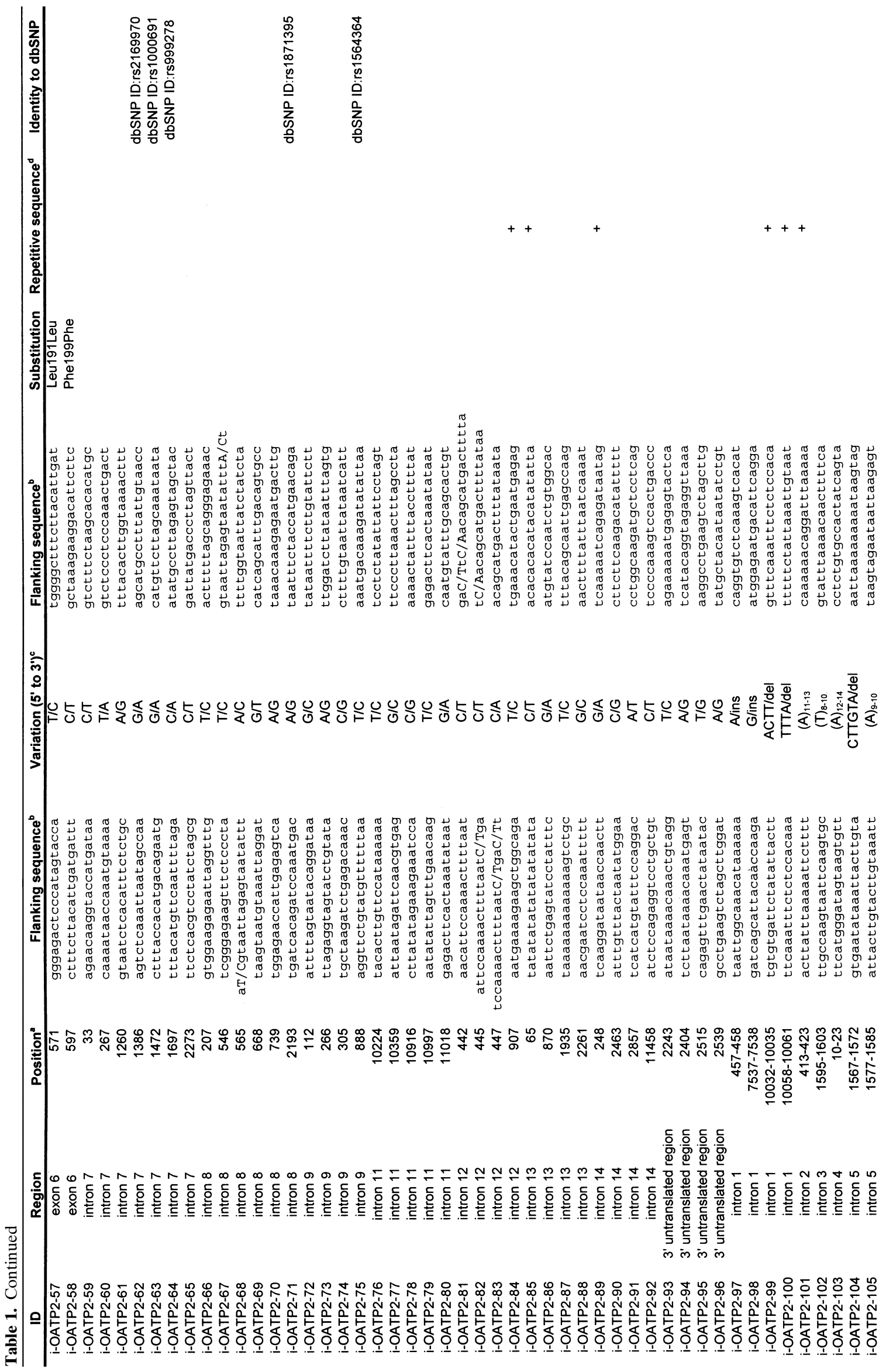




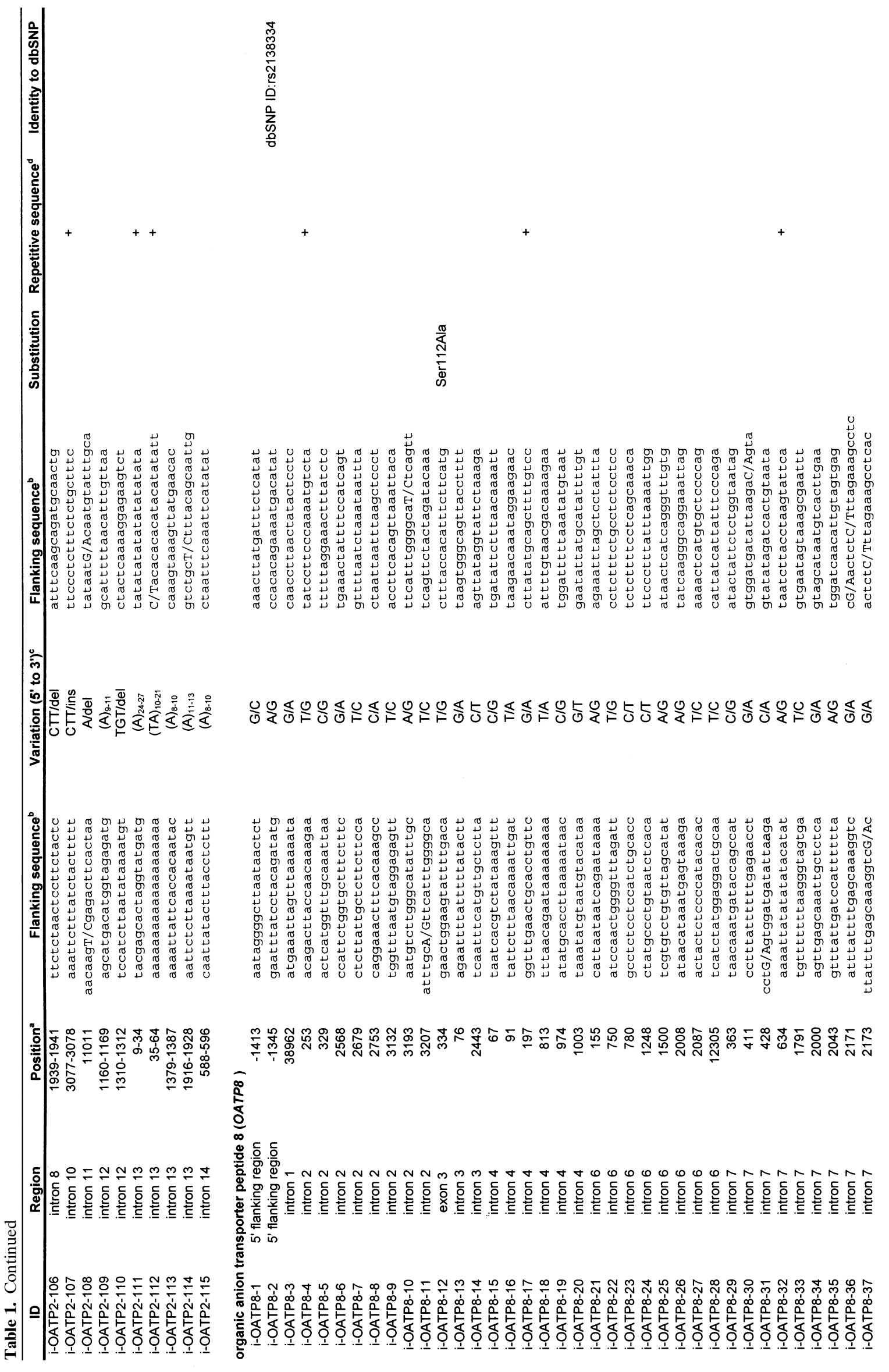




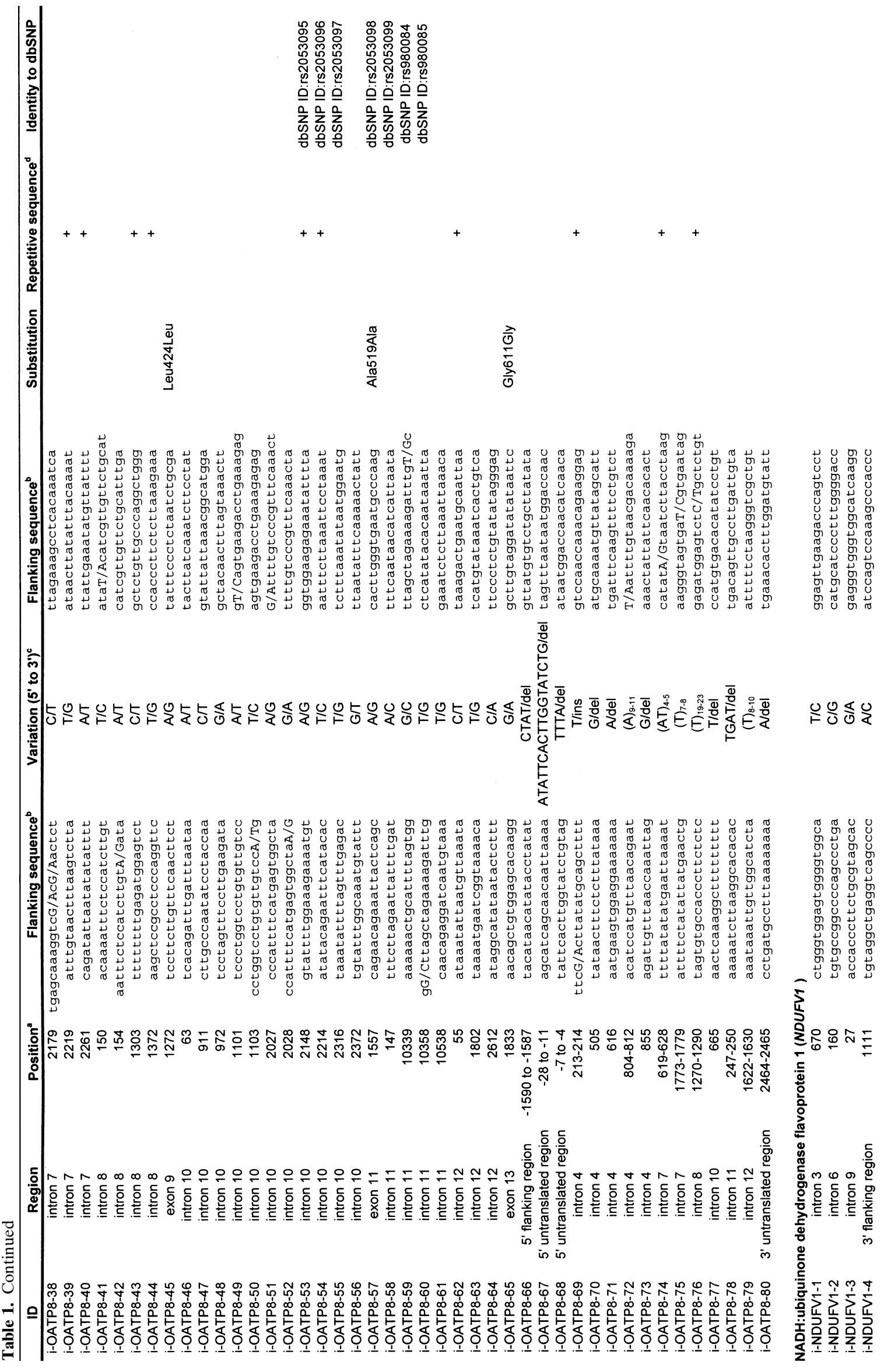




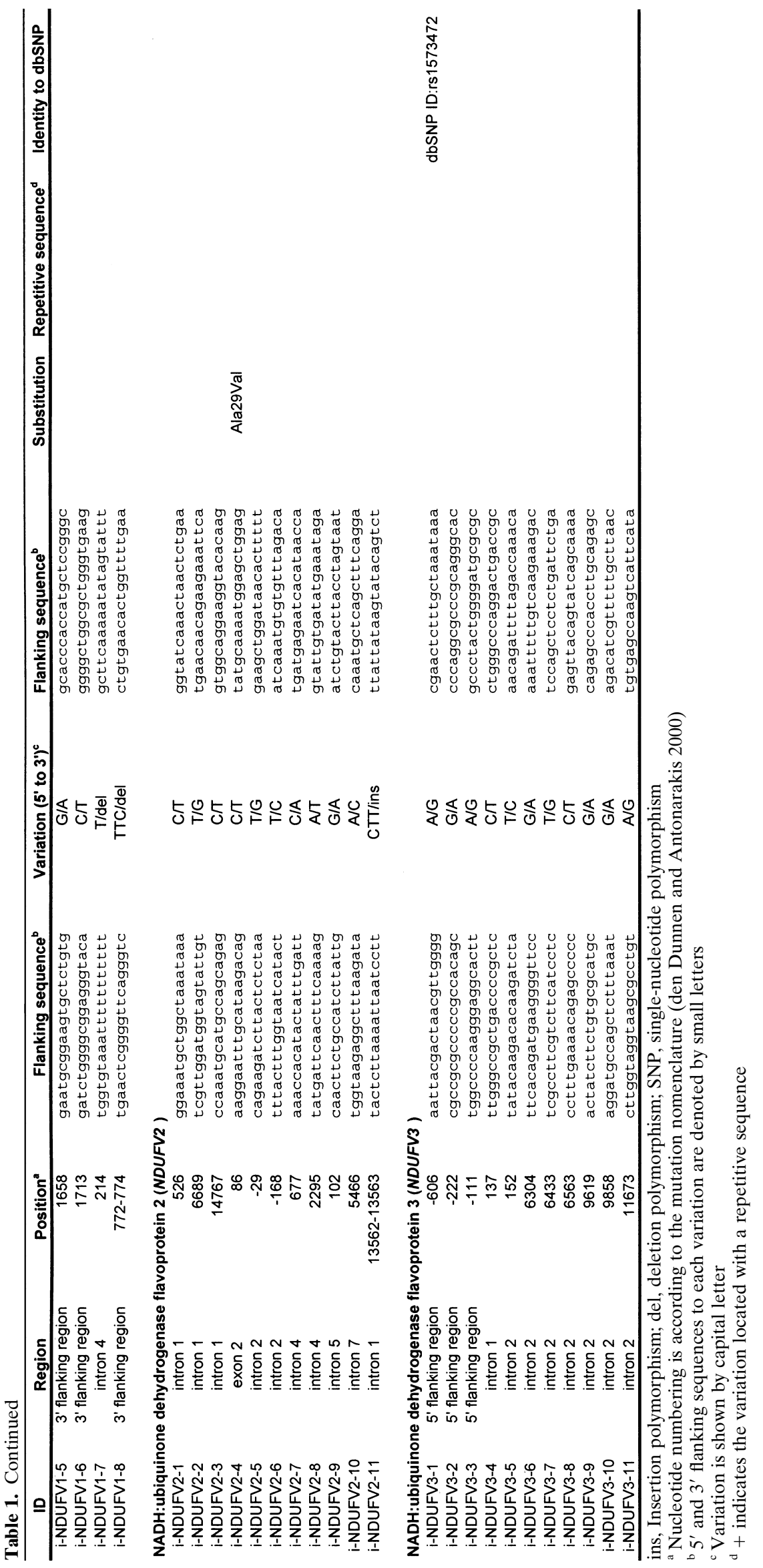


drugs. The exon organization of each gene and locations of identified SNPs are illustrated schematically in Fig. 1 (see also Table 1). By comparing our data with SNPs deposited in the dbSNP database (National Center for Biotechnology Information [NCBI]), we determined that $236(91.5 \%)$ were novel as of the middle of July 2001.

\section{$h O A T$ gene family}

A total of 25 SNPs were identified from these three loci: 2 in $5^{\prime}$ flanking regions, 3 in 5' untranslated regions, 3 in coding regions, 15 in introns, 1 in a $3^{\prime}$ untranslated region, and 1 in a $3^{\prime}$ flanking region. The genomic regions screened included $9.4 \mathrm{~kb}$ for $h O A T 1,7.9 \mathrm{~kb}$ for $h O A T 2$, and $13.5 \mathrm{~kb}$ for hOAT3; the distribution of SNPs in these three loci was one per $1232 \mathrm{bp}$ on average. Frequencies of substitutions by type were $44 \%$ for $\mathrm{A} / \mathrm{G}, 24 \%$ for $\mathrm{C} / \mathrm{T}, 16 \%$ for $\mathrm{A} / \mathrm{C}, 8 \%$ for $\mathrm{C} / \mathrm{G}$, $4 \%$ for $\mathrm{G} / \mathrm{T}$, and $4 \%$ for T/A. Regarding SNPs within coding elements (cSNP), all three such substitutions we detected among 96 Japanese chromosomes were synonymous: one was $1269 \mathrm{C}>\mathrm{T}$ (Ser423Ser) in exon 7 of the $h O A T 2$ gene; the other two were in the hOAT3 gene: $153 \mathrm{G}>\mathrm{A}$ (Pro51Pro) in exon 2 and 723T $>$ A (Thr241Thr) in exon 5. However, the two SNPs we found within the $5^{\prime}$ flanking region (putative promoter) of the $h O A T 3$ gene could affect the quantity of the gene product. We also found four insertion-deletion polymorphisms in the $h O A T 1$ and $h O A T 3$ loci.

\section{hOATP gene family}

A total of 206 SNPs were identified among the three hOATP loci: 12 in $5^{\prime}$ flanking regions, 9 in coding regions, 176 in introns, 5 in $3^{\prime}$ untranslated regions, and 4 in $3^{\prime}$ flanking regions. None were identified in $5^{\prime}$ untranslated regions. We screened $27 \mathrm{~kb}$ of genomic DNA for $h O A T P 1$, $36.5 \mathrm{~kb}$ for $h O A T P 2$, and $21.8 \mathrm{~kb}$ for $h O A T P 8$. The overall distribution of SNPs in this gene family was one per $414 \mathrm{bp}$, on average. The frequencies of different types of substitution were $36.9 \%$ for $\mathrm{A} / \mathrm{G}, 27.2 \%$ for $\mathrm{C} / \mathrm{T}, 7.8 \%$ for $\mathrm{A} / \mathrm{C}$, $9.2 \%$ for $\mathrm{C} / \mathrm{G}, 11.2 \%$ for $\mathrm{G} / \mathrm{T}$, and $7.8 \%$ for $\mathrm{T} / \mathrm{A}$. Among the 9 SNPs located in coding regions, 4 would affect amino acid sequence: $388 \mathrm{~A}>\mathrm{G}$ (Asn130Asp) and 452A $>\mathrm{G}$ (Asn151Ser) in exon 5 and $521 \mathrm{~T}>\mathrm{C}$ (Val174Ala) in exon 6 of the $h O A T P 2$ gene, and $334 \mathrm{~T}>\mathrm{G}$ (Ser112Ala) in exon 3 of the hOATP8 gene. Tamai et al. (2000) had already reported two of these (Asn130Asp and Val174Ala in the hOATP2 gene) in the process of cDNA cloning. It is not yet clear whether these SNPs affect transporter properties in hepatic excretion of drugs; a detailed genotyping study is required to clarify a relationship between these SNPs and functional properties of hOATP2 protein. According to an analysis of the promoter region of the $h O A T P 1$ gene by Kullak-Ublick et al. (1997), $i-O A T P 1-1$ is located within a putative HNF1-binding site, and $i-O A T P 1-3$ is located in a region corresponding to a putative silencer element (-662/-440). In addition, $i-O A T P 1-46$ (-188-189insA) is located in the minimal promoter region. These SNPs within $5^{\prime}$ flanking regions (putative promoters) could affect quantities of the gene products. We also found a total of 39 insertion-deletion polymorphsims among these three genes.

\section{NDUFV gene family}

Among the three NDUFV loci, we identified a total of 27 SNPs: 3 in $5^{\prime}$ flanking regions, 1 in a coding region, 20 in introns, and 3 in $3^{\prime}$ flanking regions. None were found in any $5^{\prime}$ or $3^{\prime}$ untranslated regions. We screened an $8.7-\mathrm{kb}$ genomic region for $N D U F V 1$, a $15.8-\mathrm{kb}$ region for $N D U F V 2$, and a 5.8-kb region for NDUFV3; distribution of SNPs was one in $1122 \mathrm{bp}$, on average. The substitutions in this gene family consisted of A/G (37\%), C/T (33.3\%), A/C (11.1\%), C/G (3.7\%), G/T (11.1\%), and T/A (3.7\%). The single SNP we found in a coding region changed alanine to valine at codon 29 in exon 2 of the NDUFV 2 gene. Hattori et al. (1998) reported that the frequency of homozygosity for valine at codon 29 was significantly higher in patients with Parkinson's disease than in control subjects $(23.8 \%$ vs. $11.5 \%$, Fisher's exact probability test, $p=0.0099)$. Computer analysis predicted that substitution at this residue is likely to alter the secondary structure of the gene product from an $\alpha$-helix conformation in the C-terminal domain of the signal peptide to a $\beta$-sheet structure. Homozygosity for valine increases the risk of Parkinson's disease 2.4-fold. We identified three other types of variations in this gene family as well (Table 1).

The high-resolution map we are presenting here will serve as a useful resource for analyzing potential associations between variations at these nine loci and susceptibility to common diseases as well as efficacy and/or side effects of drugs. We believe that in the near future, using the SNPbased genotyping approach to predict individual differences in response to drugs on the basis of genetic factors will be a realistic approach to treatment of human diseases or toxic conditions. Finally, we hope that the virtual experiments made possible by our catalog will accelerate certain aspects of human genetic research.

\section{References}

Abe T, Kakyo M, Tokui T, Nakagomi R, Nishio T, Nakai D, Nomura H, Unno M, Suzuki M, Naitoh T, Matsuno S, Yawo H (1999) Identification of a novel gene family encoding human liver-specific organic anion transporter LST-1. J Biol Chem 274:17159-17163

Ali ST, Duncan AM, Schappert K, Heng HH, Tsui LC, Chow W, Robinson BH (1993) Chromosomal localization of the human gene encoding the 51-kDa subunit of mitochondrial complex I (NDUFV1) to $11 \mathrm{q} 13$. Genomics $18: 435-439$

Benit P, Chretien D, Kadhom N, de Lonlay-Debeney P, CormierDaire V, Cabral A, Peudenier S, Rustin P, Munnich A, Rotig A (2001) Large-scale deletion and point mutations of the nuclear NDUFV1 and NDUFS1 genes in mitochondrial complex I deficiency. Am J Hum Genet 68:1344-1352

Bossuyt X, Muller M, Meier PJ (1996) Multispecific amphipathic substrate transport by an organic anion transporter of human liver. $\mathbf{J}$ Hepatol 25:733-738 
Cha SH, Sekine T, Fukushima JI, Kanai Y, Kobayashi Y, Goya T, Endou H (2001) Identification and characterization of human organic anion transporter 3 expressing predominantly in the kidney. Mol Pharmacol 59:1277-1286

de Coo R, Buddiger P, Smeets H, Geurts van Kessel A, MorganHughes J, Weghuis DO, Overhauser J, van Oost B (1995) Molecular cloning and characterization of the active human mitochondrial NADH:ubiquinone oxidoreductase 24-kDa gene (NDUFV2) and its pseudogene. Genomics 26:461-466

de Coo RF, Buddiger P, Smeets HJ, van Oost BA (1997) Molecular cloning and characterization of the human mitochondrial NADH:oxidoreductase 10-kDa gene (NDUFV3). Genomics 45:434437

de Coo RF, Buddiger PA, Smeets HJ, van Oost BA (1999) The structure of the human NDUFV1 gene encoding the 51-kDa subunit of mitochondrial complex I. Mamm Genome 10:49-53

den Dunnen JT, Antonarakis SE (2000) Mutation nomenclature extensions and suggestions to describe complex mutations: a discussion. Hum Mutat 15:7-12

Hattori N, Yoshino H, Tanaka M, Suzuki H, Mizuno Y (1998) Genotype in the $24-\mathrm{kDa}$ subunit gene (NDUFV2) of mitochondrial complex I and susceptibility to Parkinson disease. Genomics 49:5258

Hsiang B, Zhu Y, Wang Z, Wu Y, Sasseville V, Yang WP, Kirchgessner TG (1999) A novel human hepatic organic anion transporting polypeptide (OATP2). Identification of a liver-specific human organic anion transporting polypeptide and identification of rat and human hydroxymethylglutaryl-CoA reductase inhibitor transporters. J Biol Chem 274:37161-37168

Iida A, Sekine A, Saito A, Kitamura Y, Kitamoto T, Osawa S, Mishima C, Nakamura Y (2001a) Catalog of 320 single nucleotide polymorphisms (SNPs) in 20 quinone oxidoreductase and sulfotransferase genes. J Hum Genet 46:225-240

Iida A, Saito S, Sekine A, Kitamoto T, Kitamura Y, Mishima C, Osawa S, Kondo K, Harigae S, Nakamura Y (2001b) Catalog of 434 single nucleotide polymophisms (SNPs) in genes of the alcohol dehydrogenase, glutathione S-transferase, and nicotinamide adenine dinucleotide, reduced (NADH) ubiquinone oxidoreductase families. J Hum Genet 46:385-407

Iida A, Satio S, Sekine A, Kitamura Y, Kondo K, Mishima C, Osawa S, Harigae S, Nakamura Y (2001c) High-density single-nucleotide polymorphism (SNP) map of the $150-\mathrm{kb}$ region corresponding to the human ATP-binding cassette transporter A1 ( $A B C A 1)$ gene. J Hum Genet 46:522-528

Iida A, Satio S, Sekine A, Harigae S, Osawa S, Mishima C, Kondo K, Kitamura Y, Nakamura Y (2001d) Catalog of 46 single nucleotide polymorphisms (SNPs) in the microsomal glutathione S-transferase 1 (MGST1) gene. J Hum Genet 46:590-594

Jacquemin E, Hagenbuch B, Stieger B, Wolkoff AW, Meier PJ (1994) Expression cloning of a rat liver $\mathrm{Na}(+)$-independent organic anion transporter. Proc Natl Acad Sci USA. 91:133-137
Kok LD, Siu SS, Fung KP, Tsui SK, Lee CY, Waye MM (2000) Assignment of liver-specific organic anion transporter (SLC22A7) to human chromosome 6 bands p21.2 $\rightarrow$ p21.1 using radiation hybrids. Cytogenet Cell Genet 88:76-77

Konig J, Cui Y, Nies AT, Keppler D (2000a) A novel human organic anion transporting polypeptide localized to the basolateral hepatocyte membrane. Am J Physiol Gastrointest Liver Physiol 278:G156164

Konig J, Cui Y, Nies AT, Keppler D (2000b) Localization and genomic organization of a new hepatocellular organic anion transporting polypeptide. J Biol Chem 275:23161-23168

Kullak-Ublick GA, Hagenbuch B, Stieger B, Schteingart CD, Hofmann AF, Wolkoff AW, Meier PJ (1995) Molecular and functional characterization of an organic anion transporting polypeptide cloned from human liver. Gastroenterology 109:1274-1282

Kullak-Ublick GA, Beuers U, Fahney C, Hagenbuch B, Meier PJ, Paumgartner G (1997) Identification and functional characterization of the promoter region of the human organic anion transporting polypeptide gene. Hepatology 26:991-997

Nickerson DA, Tobe VO, Taylor SL (1997) PolyPhred: automating the detection and genotyping of single nucleotide substitutions using fluorescence-based resequencing. Nucleic Acids Res 25:2745-2751

Ohnishi Y, Tanaka T, Ozaki K, Yamada R, Suzuki H, Nakamura Y (2001) A high-throughput SNP typing system for genome-wide association studies. J Hum Genet 46:471-477

Saito S, Iida A, Sekine A, Eguchi C, Miura Y, Nakamura Y (2001a) Seventy genetic variations in human microsomal and soluble epoxide hydrolase (EPHX1 and EPHX2) genes in the Japanese population. J Hum Genet 46:325-329

Saito S, Iida A, Sekine A, Miura Y, Sakamoto T, Ogawa C, Kawauchi S, Higuchi S, Nakamura Y (2001b) Identification of 197 genetic variations in six human methyltransferase genes in the Japanese population. J Hum Genet 46:529-537

Sekine T, Cha SH, Endou H (2000) The multispecific organic anion transporter (OAT) family. Pflugers Arch 440:337-350

Sekine A, Saito S, Iida A, Mitsunobu Y, Higuchi S, Harigae S, Nakamura Y (2001) Identification of single-nucleotide polymorphisms (SNPs) of human N-acetyltransferase genes NAT1, NAT2, $A A N A T, A R D 1$ and LICAM in the Japanese population. J Hum Genet 46:314-319

Smeitink J, van den Heuvel L (1999) Human mitochondrial complex I in health and disease. Am J Hum Genet 64(6):1505-1510

Sweet DH, Bush KT, Nigam SK (2001) The organic anion transporter family: from physiology to ontogeny and the clinic. Am J Physiol Renal Physiol 281:F197-205

Tamai I, Nezu J, Uchino H, Sai Y, Oku A, Shimane M, Tsuji A (2000) Molecular identification and characterization of novel members of the human organic anion transporter (OATP) family. Biochem Biophys Res Commun 273:251-260

Walker JE (1992) The NADH:ubiquinone oxidoreductase (complex I) of respiratory chains. Q Rev Biophys 25:253-324 